\title{
Citrate to Creatinine Ratio Measurement
}

National Cancer Institute

\section{Source}

National Cancer Institute. Citrate to Creatinine Ratio Measurement. NCI Thesaurus. Code C122110.

The determination of the ratio of citrate to creatinine present in a sample. The measurement by be expressed as a ratio or percentage. 